\title{
Determination of urinary D-/L-arabinitol ratios as a biomarker for invasive candidiasis in children with cardiac diseases
}

Teresa J. Stradomska, ${ }^{1}$ Dorota Sobielarska, ${ }^{2}$ Zbigniew Mielniczuk, ${ }^{1}$
Dorota Jagiełłowicz, ${ }^{2}$ Małgorzata Syczewska ${ }^{3}$ and Danuta Dzierżanowska ${ }^{4}$

\begin{abstract}
Correspondence
Teresa J. Stradomska

jstradomska@op.pl
\end{abstract}

Received 9 December 2009

Accepted 12 August 2010

\author{
${ }^{1}$ Department of Biochemistry and Experimental Medicine, Children's Memorial Health Institute, \\ Aleja Dzieci Polskich 20, 04-730 Warsaw, Poland \\ ${ }^{2}$ Department of Cardiology, Children's Memorial Health Institute, Aleja Dzieci Polskich 20, \\ 04-730 Warsaw, Poland \\ ${ }^{3}$ Department of Pediatric Rehabilitation, Children's Memorial Health Institute, \\ Aleja Dzieci Polskich 20, 04-730 Warsaw, Poland \\ ${ }^{4}$ Department of Clinical Microbiology and Immunology, Children's Memorial Health Institute, \\ Aleja Dzieci Polskich 20, 04-730 Warsaw, Poland
}

\begin{abstract}
A non-invasive, non-culture-based method of determining urinary D-/L-arabinitol (D-/L-ARA) ratios was investigated as a tool for the diagnosis of invasive candidiasis in nosocomial paediatric infection cases. The study encompassed 138 children aged 4 days to 16 years (mean $\pm \mathrm{SD}=1.6 \pm 4.2$ years) with congenital heart defects $(91.4 \%)$ or with rhythm disorders or circulatory failure (8.6\%). ARA enantiomers were detected by GC using an electron capture detector. Positive D-/L-ARA ratios were found for $11 / 11$ patients with proven candidiasis and $17 / 19$ patients with clinically suspected invasive candidiasis. Thirty children were undergoing antifungal chemotherapy. D-/L-ARA ratios (mean \pm SD) were $2.601 \pm 0.544$ in hospitalized cardiac patients without fungal infection and $5.120 \pm 1.253$ in those receiving antifungal therapy $(P<0.001)$. The sensitivity of the method was $100 \%$, the specificity $97.2 \%$, the positive predictive value was $78.6 \%$ and the negative predictive value was $100 \%$.
\end{abstract}

\section{INTRODUCTION}

Progress in modern methods of cardiac diagnostics and cardiac surgery has significantly improved the detection and effectiveness of treating these conditions, even early in life. Unfortunately, the development of highly specialized treatment modalities has been accompanied by an increased incidence of nosocomial infections. Although Staphylococcus spp., Enterococcus spp. and Pseudomonas spp. are considered to be the main pathogens responsible for nosocomial cardiac infection (Giamarellou, 2002; Levy et al., 2003), in recent decades a significant rise in infections caused by Candida spp., particularly Candida albicans and, increasingly, Candida parapsilosis, has been noted (Weems, 1992; Ellis et al., 2001; Benjamin et al., 2004; Tissières et al., 2005).Children with congenital heart defects or circulatory disorders are at high risk of fungal infections as treatment is often invasive (including surgery) and they are frequently hospitalized in intensive care units, have immune disorders, undergo long-term antibiotic

Abbreviations: ARA, arabinitol; NPV, negative predictive value; PPV, positive predictive value. treatment and are hospitalized for long periods (MacDonald et al., 1998; Zaoutis et al., 2004).

Cultures are the standard method of diagnosing infections. Although they are effective in bacterial infections, the sensitivity of various blood culture systems is unsatisfactory with respect to fungal infections (24-53\%), with many patients with disseminated infections having negative culture results (McDonald et al., 2001; Benjamin et al., 2003). The absence of typical clinical features, and a lack of fast and satisfactory microbiological methods make the final diagnosis in patients with a suspicion of fungal infection very difficult.

D-Arabinitol (D-ARA) is a characteristic major biomarker of several Candida species (Bernard et al., 1981). GC, a rapid alternative to culture, has been used to determine the D-/L-ARA ratio in urine samples (Roboz, 1994; Larsson et al., 1994; Reiss et al., 2000; Stradomska \& Mielniczuk, 2002). In an earlier study addressing the urinary D-/L-ARA ratio as a function of age, we determined the normal values for age in children (Stradomska \& Mielniczuk, 2002). The objective of the current study was to determine the urinary D-/L-ARA ratios in a group of children undergoing 
cardiological treatment and to evaluate the usefulness of this diagnostic method in identifying Candida infections in this risk group.

\section{METHODS}

Study population and case definition. Among 4143 patients hospitalized in the Cardiology Department of the Children's Memorial Health Institute over a 3 year period, a total of 138 children aged from 4 days to 16 years (mean $\pm \mathrm{SD}=1.6 \pm 4.2$ years) was studied. The age profile of this group was: $\leqslant 1$ year (range 4 days -1 year), $46.4 \% ;>1$ to $\leqslant 3$ years (range $1.1-3$ years), $26.8 \%$; $>3$ to $\leqslant 7$ years (range $3.1-7$ years), $15.9 \% ;>10$ years (range $11-16$ years), $10.9 \%$. The primary disease was a congenital heart defect in $91.4 \%$ of the patients and rhythm disorders or circulatory failure in $8.6 \%$. All of the children were considered to be at high risk of invasive candidiasis: $91.4 \%$ were treated in the intensive care unit, $93.5 \%$ had central venous catheters and $90.6 \%$ underwent cardiac surgery.

The patients were grouped as follows: group A comprised hospitalized children with a heart defect or cardiac disease without fungal infection, whilst group B comprised 30 children who presented clinical signs of fungal infection, had a fever $>38.8{ }^{\circ} \mathrm{C}$, did not respond to broad-spectrum antibiotic treatment (3-5 days) and were treated with antifungal chemotherapy. Group B patients were subdivided into subgroups: $B_{1}$, those with microbiologically proven candidiasis with positive blood cultures; $\mathrm{B}_{2}$, those with Candida antigenaemia; and $B_{3}$, those with suspected but unproven candidiasis.

Invasive candidiasis was clinically suspected in patients presenting clinical signs of infection, a fever $>38.8{ }^{\circ} \mathrm{C}$ and not responding to broad-spectrum antibiotic treatment. Empirical antifungal treatment was instituted despite blood cultures for Candida and the remaining mycological tests being negative. None of the studied patients had Candida funguria during the study.

Urine samples were collected from each patient 4-7 days after hospitalization; subsequent samples were obtained, depending on clinical condition, every 2-4 days after the onset of fever and the start of antibiotic treatment, and 2-5 days after the start of antifungal therapy. Altogether, 389 urine samples were collected, with a mean $\pm \mathrm{SD}$ of $2.8 \pm 4.2$ samples per patient (range $1-11$ per patient). The mean numbers of specimens per patient for each group were: group $C$ (controls), 1.0; group $A, 1.1$; group $B_{1}, 5.8$; group $B_{2}, 6.1$; and group $B_{3}, 6.3$. The control group $(C)$ comprised 80 healthy children ranging in age from 1 month to 13 years without clinical symptoms of either superficial or invasive candidiasis. The highest peak values of D-/L-ARA were used for analysis state for each patient.

GC and microbiological analysis. Samples $(\sim 2 \mathrm{ml}$ urine $)$ were collected from patients and stored at $-20{ }^{\circ} \mathrm{C}$ before analysis. The D-/L-ARA ratio was determined as trifluoroacetic derivatives according to a previously described method (Stradomska \& Mielniczuk, 2002).

The BacT/Alert method was used for blood cultures. Candida was cultured on Sabouraud agar from samples of blood, urine and mucous membranes. The serum of each child was tested for the presence of Candida antigen using the Pastorex Candida test and for anti-Candida mannan antibodies with an immunofluorescence test (Gutiérrez et al., 1993).

Statistical analysis. The results are presented as means \pm SD. The significance of the differences was determined by the Levene test for determining the homogeneity of variances, and an analysis of variance Kruskal-Wallis rank test was applied to compare the three samples. All $P$ values $<0.05$ were considered significant.

\section{RESULTS AND DISCUSSION}

The urinary D-/L-ARA ratios (means $\pm \mathrm{SD}$ ) and results of microbiological analysis in the studied groups are presented in Table 1. The urinary D-/L-ARA ratios in children according to age subgroup are given in Table 2. The mean urinary D-/L-ARA ratios in group A were higher than in the control group $\mathrm{C}$ in the respective age groups and declined with age. The distribution of D-/L-ARA levels in groups A and $\mathrm{B}$ was normal. The differences in D-/L-ARA ratios among the three groups (A, B and C) were statistically significant $(P<0.001)$. The normal range of urinary $\mathrm{D}-/ \mathrm{L}-$ ARA levels was defined (mean $\pm 2 \mathrm{SD}$ ) on the basis of findings from a study of healthy children as was the cut-off limit (mean $\pm 3 \mathrm{SD}$ ) for diagnosis of candidiasis (Table 2).

In 108 hospitalized children with cardiac disease but without fungal infection (group A), the mean D-/L-ARA level was higher than in the control group of healthy children $(2.601 \pm 0.544$ vs $2.21 \pm 0.626)$, but was still within the upper normal range. The results of microbiological tests remained within normal limits, and blood cultures for Candida species were negative, as was the test for Candida antigen, with mannan antibodies at normal levels (Table 1). Three patients without evidence of invasive candidiasis had above-normal D-/L-ARA ratios. In one of these patients, this value later normalized, whilst in two it remained elevated.

Elevated D-/L-ARA ratios were found in the 30 children in group B: $5.120 \pm 1.253$ (range 3.8-8.2) (Table 1). All of them presented clinical signs of infection. Their temperature remained constant or rose to $40.5{ }^{\circ} \mathrm{C}$, and they did not respond to broad-spectrum antibiotics.

The 11 patients in group $B_{1}$ were diagnosed with invasive candidiasis on the basis of positive blood cultures for Candida. All of these patients had D-/L-ARA ratios elevated to above cut-off levels $(5.209 \pm 0.735)$. In group $B_{2}$, the five patients were Candida antigen positive and had antibody levels $>1: 160$. All these patients also had positive D-/L-ARA ratios (mean $4.730 \pm 0.659$; Table 1, Fig. 1). Both groups of patients received antifungal chemotherapy (fluconazole or amphotericin B). In all of these patients, the value of the D-/L-ARA biomarker suggested infection. The D-/L-ARA ratio for groups $B_{1}$ and $B_{2}$ was $5.034 \pm 0.792$.

Fever also persisted in each of the remaining 14 patients (group $\mathrm{B}_{3}$ ), despite antibiotic treatment, and it was not possible to establish a cause. Despite the results of mycological blood cultures for Candida being negative, and Candida antigens and serological tests for antibodies being within normal limits, these patients were classified as having clinically suspected but unproven invasive candidiasis and received empirical antifungal therapy. Three of these patients had Candida colonization of mucosal membranes. Two children had D-/L-ARA levels of 3.8-3.9 (subgroup 1-3 years), which was below the pathological cut-off value (mean $\pm 3 \mathrm{SD}=4.0$ ), but above the normal range. The D-/L-ARA ratio in this group was $5.322 \pm 1.590$ 
Table 1. Urinary D-/L-ARA levels in children with heart defects or cardiac disease

\begin{tabular}{|lccccc|}
\hline Group & $\begin{array}{c}\text { D-/L-ARA ratio } \\
(\text { mean } \pm \text { SD })\end{array}$ & $\begin{array}{c}\text { D-/L-ARA ratio } \\
(\text { range })\end{array}$ & Blood culture & $\begin{array}{c}\text { Pastorex Candida } \\
\text { antigen test }\end{array}$ & $\begin{array}{c}\text { Anti-Candida mannan } \\
\text { antibodies* }\end{array}$ \\
\hline $\mathrm{A}(n=108)$ & $2.601 \pm 0.544$ & $1.7-4.3$ & - & - & $1: 10-1: 40$ \\
$\mathrm{~B}(n=30)$ & $5.120 \pm 1.253$ & $3.9-8.2$ & $+(n=11) ;-(n=19)$ & $+(n=5)$ & $1: 40-1: 640$ \\
$\mathrm{~B}_{1}(n=11)$ & $5.209 \pm 0.735$ & $4.5-6.9$ & + & - & $1: 20-1: 80$ \\
$\mathrm{~B}_{2}(n=5)$ & $4.730 \pm 0.659$ & $4.1-5.85$ & - & - & $1: 160-1: 640$ \\
$\mathrm{~B}_{3}(n=14)$ & $5.322 \pm 1.590$ & $3.9-8.2$ & $\mathrm{ND}$ & $\mathrm{ND}$ \\
$\mathrm{C}($ control $)(n=80)$ & $2.210 \pm 0.626$ & $1.3-3.3$ & & & $1: 10-1: 80$ \\
\hline
\end{tabular}

ND, Not determined.

${ }^{\star}$ Normal range $1: 10-1: 80$.

(Fig. 1). No statistically significant differences were found in the levels of D-/L-ARA $(H=2.257, P>0.324)$ among groups $\mathrm{B}_{1}$ (proven invasive Candida infection), $\mathrm{B}_{2}$ (patients with Candida antigenaemia) and $\mathrm{B}_{3}$ (clinically suspected invasive candidiasis).

During antifungal chemotherapy, D-/L-ARA levels were normalized in $11 / 11$ patients with proven candidiasis (group $B_{1}$ ), and in $5 / 5$ patients with antigenaemia (group $B_{2}$ ), but only in $11 / 14$ patients in group $B_{3}$ with suspected but unproved candidiasis. In summary, antifungal therapy led to clinical improvement and normalization of D-/LARA levels in 27/30 patients. The remaining three patients died without a lowering of this biochemical marker. It is very difficult to evaluate the response to antifungal treatment, particularly in dead patients. Simultaneous clinical improvement and reduced D-/L-ARA levels during antifungal treatment are indicative of probable infection. It seems that persisting clinical symptoms, with increased D-/ L-ARA ratios, can attest to possible infection. Treatment was monitored in ten patients. It appeared that D-/L-ARA ratios responded rapidly to clinical changes during treatment. Monitoring D-/L-ARA levels facilitates decision making about changing medications if the D-/L-ARA level remains high (Figs 2 and 3). However, the example of one patient (Fig. 4) showed that negative results of traditional mycological diagnostics cannot exclude fungal infection if D-/L-ARA levels are elevated.

Table 2. D-/L-ARA levels in the different age subgroups

Group A, hospitalized children with a heart defect or cardiac disease without fungal infection; group B, hospitalized children with a heart defect or cardiac disease who received antifungal treatment; group C, control group (healthy children aged 1 month-13 years). The mean age \pm SD (in years) in each particularly study subgroup is given in square brackets.

\begin{tabular}{|c|c|c|c|c|c|c|c|c|}
\hline \multirow{2}{*}{$\begin{array}{l}\text { Age } \\
\text { subgroup } \\
\text { (years) }\end{array}$} & \multicolumn{6}{|c|}{ D-/L-ARA ratio (no. of patients) $[$ mean $\pm \mathrm{SD}]$} & \multirow{2}{*}{$\begin{array}{l}\text { Normal value } \\
(\text { mean } \pm 2 \text { SD })\end{array}$} & \multirow{2}{*}{$\begin{array}{c}\text { Cut-off } \\
(\text { mean } \pm 3 \mathrm{sD})\end{array}$} \\
\hline & $\begin{array}{l}\text { Group A } \\
(n=108)\end{array}$ & $\begin{array}{c}\text { Group } B_{1} \\
(n=11)\end{array}$ & $\begin{array}{l}\text { Group } B_{2} \\
\quad(n=5)\end{array}$ & $\begin{array}{c}\text { Group } B_{3} \\
(n=14)\end{array}$ & $\begin{array}{l}\text { Group B } \\
(n=30)\end{array}$ & $\begin{array}{l}\text { Control C } \\
\quad(n=80)\end{array}$ & & \\
\hline $0-1$ & $\begin{array}{c}2.65 \pm 0.46 \\
(n=48) \\
{[0.37 \pm 0.36]}\end{array}$ & $\begin{array}{c}5.13 \pm 0.68 \\
\quad(n=4) \\
{[0.22 \pm 0.27]}\end{array}$ & $\begin{array}{c}5.22 \pm 0.88 \\
(n=2) \\
{[0.39 \pm 0.50]}\end{array}$ & $\begin{array}{c}5.32 \pm 1.63 \\
(n=8) \\
{[0.55 \pm 0.36]}\end{array}$ & $\begin{array}{c}5.16 \pm 1.32 \\
(n=16) \\
{[0.47 \pm 0.38]}\end{array}$ & $\begin{array}{c}2.48 \pm 0.58 \\
(n=23) \\
{[0.53 \pm 0.24]}\end{array}$ & 3.6 & 4.2 \\
\hline $1-3$ & $\begin{array}{c}2.61 \pm 0.50 \\
(n=28) \\
{[1.89 \pm 0.58]}\end{array}$ & $\begin{array}{c}5.60 \pm 0.92 \\
(n=4) \\
{[2.12 \pm 0.25]}\end{array}$ & $\begin{array}{c}4.30 \pm 0.28 \\
(n=2) \\
{[1.34 \pm 0.23]}\end{array}$ & $\begin{array}{c}5.38 \pm 1.91 \\
(n=6) \\
{[1.48 \pm 0.43]}\end{array}$ & $\begin{array}{c}5.14 \pm 1.37 \\
(n=9) \\
{[1.78 \pm 0.53]}\end{array}$ & $\begin{array}{c}2.30 \pm 0.58 \\
\quad(n=18) \\
{[2.19 \pm 0.62]}\end{array}$ & 3.5 & 4.0 \\
\hline $3-7$ & $\begin{array}{c}2.51 \pm 0.57 \\
(n=17) \\
{[4.63 \pm 1.47]}\end{array}$ & $\begin{array}{c}4.80 \pm 0.40 \\
(n=3) \\
{[4.51 \pm 2.17]}\end{array}$ & $\begin{array}{c}4.60 \pm 0.68 \\
(n=1) \\
{[3.50]}\end{array}$ & $\begin{array}{l}- \\
-\end{array}$ & $\begin{array}{c}4.90 \pm 1.16 \\
(n=5) \\
{[4.20 \pm 1.25]}\end{array}$ & $\begin{array}{c}2.09 \pm 0.59 \\
(n=22) \\
{[5.19 \pm 1.15]}\end{array}$ & 3.3 & 3.9 \\
\hline$>10$ & $\begin{array}{c}2.34 \pm 0.42 \\
(n=15) \\
{[14.37 \pm 2.17]}\end{array}$ & - & - & - & - & $\begin{array}{c}1.64 \pm 0.39 \\
(n=17) \\
{[14.87 \pm 1.97]}\end{array}$ & 2.4 & 2.8 \\
\hline
\end{tabular}




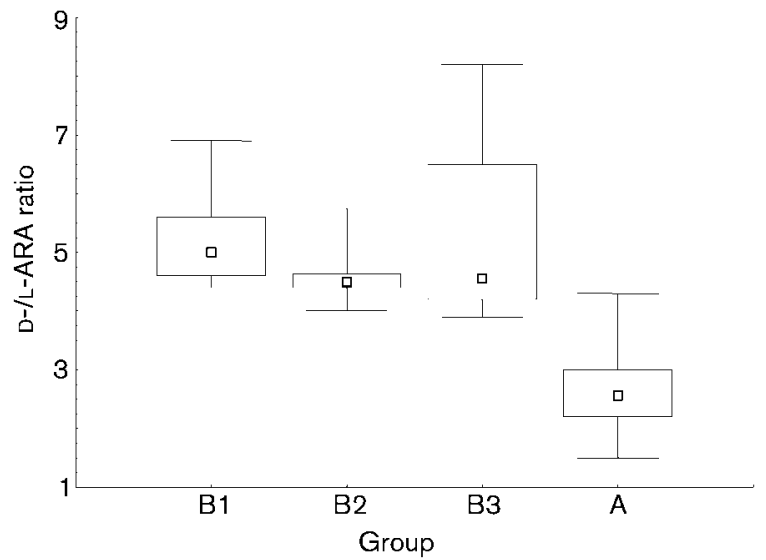

Fig. 1. Graph showing the urinary D-/L-ARA ratios in groups $A, B 1$, B2 and B3. White bars, 25-75\%; $\square$, median value; error bars, minimum-maximum values.

In group A (hospitalized children without fungal infection), a negative correlation was found between D-/L-ARA ratios and age (Table 2), which confirmed our earlier

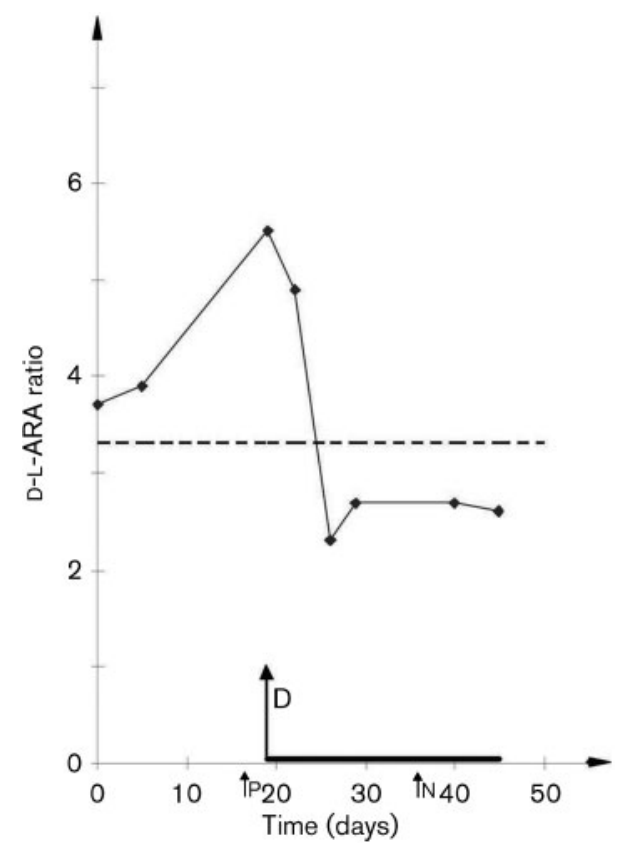

Fig. 2. Urinary $D-/ L-A R A$ ratios in a $1 \frac{1}{2}$-year-old boy with a congenital heart defect (complete atrio-ventricular septal defect; sepsis 6 months earlier). The pre-surgery D-/L-ARA ratio was 3.7. On day 6 post-surgery, the D-/L-ARA ratio rose to 5.5 and was accompanied by a deterioration in clinical condition. Fluconazole ( $\uparrow \mathrm{D})$ was started and on the sixth day the D-/L-ARA ratio normalized to 2.3 with improvement of the patient's condition. Solid line, treatment time; dashed line, upper limit of normal values; $\uparrow P$, positive blood culture for $C$. albicans; $\uparrow N$, negative blood culture for C. albicans.

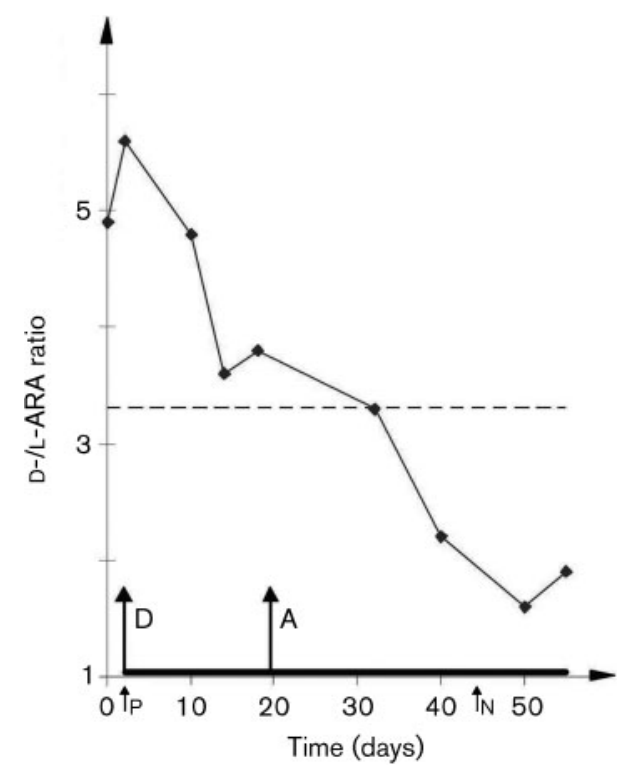

Fig. 3. Urinary $D-/ L-A R A$ ratios in a 3-year-old girl with a congenital heart defect, pneumonia, mycotic and purulent lesions of a forearm wound (C. albicans), in a serious condition with a high fever not responding to broad-spectrum antibiotic therapy. The initial D-/LARA ratio was 5.6. Fluconazole ( $\uparrow \mathrm{D})$ lowered the level of this biomarker over a period of 19 days, but improvement of the clinical condition and normalization of the D-/L-ARA ratio was achieved only after the introduction of amphotericin treatment $(\uparrow A)$.

reports on the normal values of D-/L-ARA ratios in the paediatric population (Stradomska \& Mielniczuk, 2002). Similarly to a group of at-risk hospitalized infants undergoing long-term antibiotic therapy (Stradomska et al., 2005), elevated mean D-/L-ARA ratios and medians were found in group A children in comparison with healthy children. Other authors have also observed higher urinary D-/L-ARA ratios in hospitalized children and adults (Larsson et al., 1994; Christensson et al., 1997). This rise probably reflects the high sensitivity of this biomarker to risk factors (such as antibiotic therapy and hospitalization), and its level seems to point towards an increased fungal load in hospitalized at-risk patients.

As the intervals delineated by the means and SD were nearly identical, the numbers of patients in the age subgroups low and the sets disjunctive (Table 1), it seemed justified to determine the mean results and to conduct a sensitivity and specificity analysis of this method on the entire group studied. On the basis of the results for patients in groups $B_{1}$ and $\mathrm{A}$, the sensitivity and specificity of urine ARA as a biomarker in the diagnosis of invasive candidiasis were 100 and $97.2 \%$, respectively, and the positive predictive value (PPV) and negative predictive value (NPV) were 78.6 and $100 \%$, respectively. If it is assumed that the empirically treated patients (groups $B_{2}$ and $B_{3}$ ) indeed also had invasive candidiasis, the calculated validation parameters for the ARA test were: sensitivity, $93.3 \%$; specificity, 


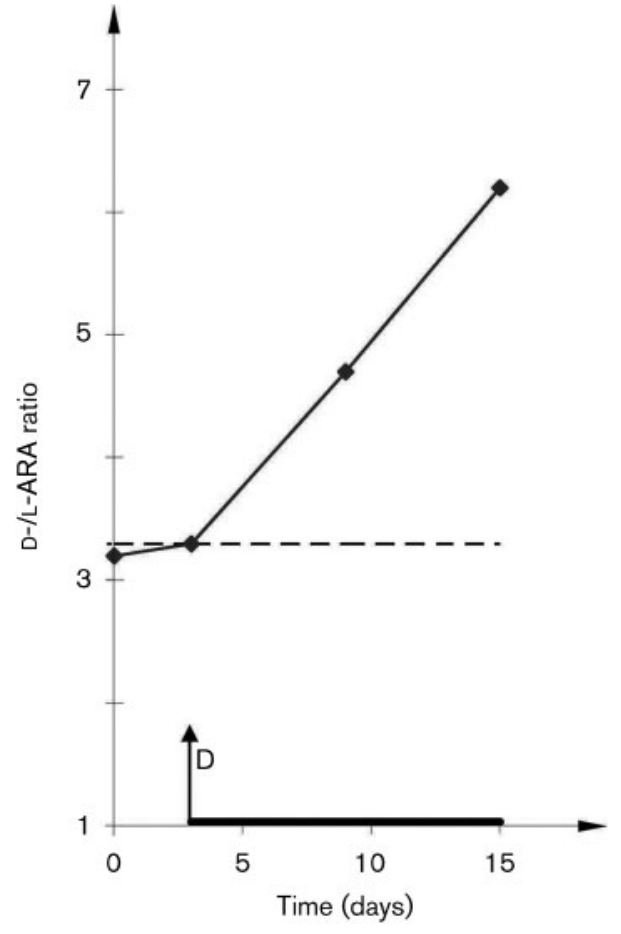

Fig. 4. Urinary $D-/ L-A R A$ ratios in a child after cardiac surgery. Despite antibiotic therapy, fever rose to $40.5{ }^{\circ} \mathrm{C}$. Although the results of mycological diagnostic tests were negative, antifungal therapy, fluconazole $(\uparrow \mathrm{D})$, was started. The D-/L-ARA ratio rose to 6.1. The patient died on day 14 of treatment.

97.2\%; false-negative results, $6.7 \%$; false-positive results, $2.8 \%$; NPV, 98.1\%; PPV, 90.9\%. The estimated diagnostic values of this method in this study are similar to those presented previously: $94 \%$ sensitivity and $88 \%$ specificity in adults (Roboz \& Katz, 1992), and $100 \%$ sensitivity and $94 \%$ specificity, with a PPV of $71 \%$ and an NPV of $100 \%$, in children with neutropenia (Christensson et al., 1997). It should be noted that assessment of the clinical utility of the reported method is based on a prevalence of 30/138. If the ARA test were to be used for screening for invasive candidiasis in the hospital, the prevalence would be $0.7 \%$ and the NPV could change significantly.

Infants (range 16 days-1 year) were the largest age group, accounting for $53.3 \%$ of group $B$, whilst children $\leqslant 3$ years (range 1.1-2.5) made up $30.0 \%$ and children aged $>3$ to $\leqslant 7$ years (range 3.5-7) comprised $16.7 \%$. Similar data ( $63 \%$ children $<1$ year) were presented in a review by Millar et al. (2005). Overall, Candida infection developed in $0.7 \%$ of the patients hospitalized in this 3 year period. Although similar data were presented by Millar et al. (2005), higher figures have been reported by others $[6.3 \%$ in infants following cardiac surgery, $10 \%$ in children with an underlying diagnosis of cardiac diseases (Chakrabarti et al., 2003; Zaoutis et al., 2004)]. The percentage of children who were given antifungal treatment (group B) in relation to the number of patients in particular age subgroups was similar $(<1$ year, $25.0 \%$; $<3$ years $24.3 \%$; $>3$ to $<7$ years, $22.7 \%$ ), but in the age group $>10$ years it was $0 \%$.

Three children in our study $(<3$ years $)$ died, despite antifungal treatment, without normalization of the biomarker; thus, mortality was $10 \%$. Mortality in children with invasive candidiasis has been reported to range from 26 to $54 \%$ in infants (McDonald et al., 2001; Zaoutis et al., 2004), but as high as $83 \%$ following cardiac surgery in children (Chakrabarti et al., 2003). C. albicans is considered to be the most virulent pathogen and also causes the highest mortality [59\% (Rabalais et al., 1996) and 26\% (Kossoff et al., 1998) have been reported], although other authors report that mortality from $C$. parapsilosis can be as high as 39\% (Saxen et al., 1995).

Successful treatment of fungal infections depends mainly on early and accurate diagnosis, and implementation of the appropriate antifungal therapy (Debusk et al., 1994; Denning et al., 2003). Diagnostic difficulties and high mortality are why prophylactic antimycotic therapy is a standard procedure in some risk groups (Rex et al., 2000; Eggimann et al., 2003). As discussed by other authors, more aggressive drugs (such as amphotericin B) are usually preferred (Rex et al., 2000; Chandrasekar, 2001). However, this approach can lead to highly resistant pathogens, which has already been observed (such as a $50 \%$ increase in Candida glabrata infections known to be resistant to fluconazole in patients after empirical treatment; Sendid et al., 2006).

In patients with fungal endocarditis, especially children, mortality reaches $70-80 \%$ due to a recurrence rate of $30 \%$. For this reason, they should be followed for up to 4 years while on prophylactic antifungal therapy (Johnston et al., 1991; Rex et al., 2000; Ellis et al., 2001). In our opinion, determining D-/L-ARA levels during treatment creates optimal conditions for monitoring the condition of a patient with deep fungal infection (aiding selection of the appropriate drug and duration of therapy; Figs 2 and 3). It may be especially helpful in managing children at risk due to cardiac disorders.

The known diagnostic difficulties (delayed or mistaken diagnosis in $82 \%$ of patients; Ellis et al., 2001) suggest that better diagnostic monitoring by heightened diagnostic acumen, including detection of other biomarkers, is required to allow earlier identification of patients at high risk of fungal infection (Ellis et al., 2001; Millar et al., 2005). Recently, a very interesting study on the clinical utility of fungal cell wall components detected as biomarkers has been presented (Ellis et al., 2008).

D-ARA (pentane-1,2,3,4,5 pentitol) belongs to the group of polyols. Polyols are involved in the pentose phosphate pathway. Studies have shown that serum D-ARA/creatinine ratios are elevated in animals and humans with invasive Candida infection compared with uninfected or colonized 
controls (Wong et al., 1982). Comparison of serum D-ARA secretion with creatinine has made it possible to eliminate false-positive results for renal dysfunction patients. The experiments by Roboz (1994) and our unpublished results show that serum D-/L-ARA 'translates into' urine D-/LARA. In addition, this marker is not influenced by renal dysfunction. The availability of material and the noninvasiveness of the test, and thus the possibility of taking multiple samples, are why we determine urinary ARA levels, especially because the study dealt with the paediatric population. It must be noted that the measured D-/L-ARA ratio is a product of human D-/L-ARA and, possibly, a metabolite of Candida sp. existing in the host. The D-/LARA ratio rises if the D-ARA concentration increases or if the L-ARA concentration decreases. The pentose pathway in humans is not well understood. Metabolic dysfunctions or disorders in the pathways of polyols may affect the diagnostic value of the D-/L-ARA ratio. In recent years, new diseases involving disorders of polyol metabolism resulting in accumulation of D-ARA in body fluid have been found, which may generate false-positive results. Also, one child with L-arabinosuria has been reported, which may, in turn, cause false-negative results. Nevertheless, these are very rare cases and are accompanied by other clinical symptoms (Tylki-Szymańska et al., 2009). However, relatively less is known about ARA enantiomer secretion, metabolism and kinetics, which may cause some potential problems with interpreting results.

Earlier reports on increases in D-/L-ARA ratios preceding positive blood culture results by 1-3 weeks (Christensson et al., 1997; Walsh et al., 1995), and clinical experience from other medical centres (Yeo et al., 2006; Sigmundsdottir et al., 2007), as well as the results presented above, support the suggestion that the use of the described method in combination with traditional methods can improve the reliability of fungal infection diagnosis and facilitate the early initiation of antifungal treatment. The reported method does not permit the identification of the pathogen in terms of species, but because the assayed metabolite is produced mainly by the major aetiological factor (Millar et al., 2005), Candida spp., and given the rapidity, noninvasiveness and micro-scale of the assay, it should be a useful tool in the diagnosis of fungal infections in the panel of diagnostic methods used for children at risk.

\section{REFERENCES}

Benjamin, D. K., Jr, DeLong, E. R., Steinbach, W. J., Cotton, C. M., Walsh, T. J. \& Clark, R. H. (2003). Empirical therapy for neonatal candidemia in very low birth weight infants. Pediatrics 112, 543-547.

Benjamin, D. K., Jr, Miro, J. M., Hoen, B., Steinbach, W. J., Fowler, W. G., Jr, Olaison, L., Habib, G., Abrutyn, E., Perfect, J. \& other authors (2004). Candida endocarditis: contemporary casus from the International Collaboration of Infectious Endocarditis Merged Database (ICE-mD). Scand J Infect Dis 36, 453-455.

Bernard, E. M., Christiansen, K. J., Tsang, S., Kiehn, T. E. \& Armstrong, D. (1981). Rate of arabinitol production by pathogenic yeast species. J Clin Microbiol 14, 189-194.
Chakrabarti, C., Sood, S. K., Parnell, V. \& Rubin, L. G. (2003). Prolonged candidemia in infants following surgery for congenital heart disease. Infect Control Hosp Epidemiol 24, 753-757.

Chandrasekar, P. H. (2001). Empirical antifungal therapy for persistent fever in patients with neutropenia. Clin Infect Dis 32, 320.

Christensson, B., Wiebe, T., Pehrson, K. \& Larsson, L. (1997). Diagnosis of invasive candidiasis in neutropenic children with cancer by determination of $\mathrm{D}$-arabinitol/L-arabinitol ratios in urine. J Clin Microbiol 35, 636-640.

Debusk, C. H., Daoud, R., Thirumoorthi, M. C., Wilson, F. M. \& Khatib, R. (1994). Candidemia: current epidemiologic characteristics and a long-term follow-up of the survivors. Scand J Infect Dis 26, 697703.

Denning, D. W., Kibbler, C. C. \& Barnes, R. A. on behalf of the British Society for Medical Mycology (2003). British Society for Medical Mycology proposed standards of care for patients with invasive fungal infections. Lancet Infect Dis 3, 230-240.

Eggimann, P., Garbino, J. \& Pittet, D. (2003). Management of Candida species infections in critically ill patients. Lancet Infect Dis $\mathbf{3}$, $772-785$.

Ellis, M. E., Al-Abdely, H., Sandridge, A., Greer, W. \& Ventura, W. (2001). Fungal endocarditis: evidence in the world literature, 19651995. Clin Infect Dis 32, 50-62.

Ellis, M., al-Ramadi, B., Finkelman, M., Hedstrom, U., Kristensen, J., Ali-Zadeh, H. \& Klingspor, L. (2008). Assessment of the clinical utility of serial $\beta$-D-glucan concentrations in patients with persistent neutropenic fever. J Med Microbiol 57, 287-295.

Giamarellou, H. (2002). Nosocomial cardiac infections. J Hosp Infect 50, 91-105.

Gutiérrez, J., Maroto, C., Piédrola, G., Martín, E. \& Perez, J. A. (1993). Circulating Candida antigens and antibodies: useful markers of candidemia. J Clin Microbiol 31, 2550-2552.

Johnston, P. G., Lee, J., Domanski, M., Dressler, F., Tucker, E., Rothenberg, M., Cunnion, R. E., Pizzo, P. A. \& Walsh, T. J. (1991). Late recurrent Candida endocarditis. Chest 99, 1531-1533.

Kossoff, E. H., Buescher, E. S. \& Karlowicz, M. G. (1998). Candidemia in a neonatal intensive care unit: trends during fifteen years and clinical features of 111 cases. Pediatr Infect Dis J 17, 504508.

Larsson, L., Pehrson, C., Wiebe, T. \& Christensson, B. (1994). Gas chromatographic determination of D-arabinitol/L-arabinitol ratios in urine: a potential method for diagnosis of disseminated candidiasis. J Clin Microbiol 32, 1855-1859.

Levy, I., Ovadia, B., Erez, E., Rinat, S., Ashkenazi, S., Birk, E., Konisberger, H., Vidne, D. \& Dagan, O. (2003). Nosocomial infections after cardiac surgery in infants and children: incidence and risk factors. $J$ Hosp Infect 53, 111-116.

MacDonald, L., Baker, C. \& Chenoweth, C. (1998). Risk factors for candidemia in a children's hospital. Clin Infect Dis 26, 642645 .

McDonald, L. C., Weinstein, M. P., Fune, J., Mirrett, S., Reimer, R. G. \& Reller, L. B. (2001). Controlled comparison of BacT/ALERT FAN aerobic medium and BACTEC fungal blood culture medium for detection of fungemia. J Clin Microbiol 39, 622-624.

Millar, B. C., Jugo, J. \& Moore, J. E. (2005). Fungal endocarditis in neonates and children. Pediatr Cardiol 26, 517-536.

Rabalais, G. P., Samiec, T. D., Bryant, K. K. \& Lewis, J. J. (1996). Invasive candidiasis in infants weighing more than 2500 grams at birth admitted to a neonatal intensive care unit. Pediatr Infect Dis J 15, 348-352. 
Reiss, E., Obayashi, T., Orle, K., Yoshida, M. \& Zancopé-Oliveira, R. M. (2000). Non-culture based diagnostic tests for mycotic infections. Med Mycol 38, 147-159.

Rex, J. H., Walsh, T. J., Sobel, J. D., Filler, S. G., Pappas, P. G., Dismukes, W. E. \& Edwards, J. E. (2000). Practice guidelines for the treatment of candidiasis. Clin Infect Dis 30, 662-678.

Roboz, J. (1994). Diagnosis and monitoring of disseminated candidiasis based on serum/urine D/L-arabinitol ratios. Chirality 6, 51-57.

Roboz, J. \& Katz, R. N. (1992). Diagnosis of disseminated candidiasis based on serum D-/L-arabinitol ratios using negative chemical ionization mass spectrometry. J Chromatogr 575, 281-286.

Saxen, H. S., Virtanen, M., Carlson, P., Hoppu, K., Pohjavuori, M., Vaara, M., Vuopio-Varkila, J. \& Peltola, H. (1995). Neonatal Candida parapsilosis outbreak with a high case fatality rate. Pediatr Infect Dis $J$ 14, 776-781.

Sendid, B., Cotteau, A., François, N., D'Haveloose, A., Standaert, A., Camus, D. \& Poulain, D. (2006). Candidemia and antifungal therapy in a French University Hospital: rough trends over a decade and possible links. BMC Infect Dis 6, 80.

Sigmundsdottir, G., Larsson, L., Wiebe, T., Björklund, L. J. \& Christensson, B. (2007). Clinical experience of urine D-arabinitol/Larabinitol ratio in the early diagnosis of invasive candidiasis in paediatric high risk populations. Scand J Infect Dis 39, 146-151.

Stradomska, T. J. \& Mielniczuk, Z. (2002). Gas chromatographic determination of D-/L-arabinitol ratio in healthy Polish children. J Chromatogr B Analyt Technol Biomed Life Sci 773, 175-181.

Stradomska, T. J., Bobula-Milewska, B., Bauer, A., Mielniczuk, Z., Dąbkowska, M., Syczewska, M. \& Dzierżanowska, D. (2005).
Urinary D-/L-arabinitol levels in infants undergoing long-term antibiotic therapy. J Clin Microbiol 43, 5351-5354.

Tissières, P., Jaeggi, E. T., Beghetti, M. \& Gervaix, A. (2005). Increase of fungal endocarditis in children. Infection 33, 267-272.

Tylki-Szymańska, A., Stradomska, T. J., Wamelink, M. M. C., Salomons, G. S., Taybert, J., Pawłowska, J. \& Jakobs, C. (2009). Transaldolase deficiency in two new patients with a relative mild phenotype. Mol Genet Metab 97, 15-17.

Walsh, T. J., Merz, W. G., Lee, J. W., Schaufele, R., Sein, T., Whitcomb, P. O., Ruddel, M., Burns, W., Wingard, J. R. \& other authors (1995). Diagnosis and therapeutic monitoring of invasive candidiasis by rapid enzymatic detection of serum D-arabinitol. Am J Med 99, 164172.

Weems, J. J., Jr (1992). Candida parapsilosis: epidemiology, pathogenicity, clinical manifestations, and antimicrobial susceptibility. Clin Infect Dis 14, 756-766.

Wong, B., Bernard, E. M., Gold, J. W. M., Fong, D. \& Amstrong, D. (1982). The arabinitol appearance rate in laboratory animals and humans: estimation from the arabinitol/creatinine ratio and relevance to the diagnosis of candidiasis. J Infect Dis 146, 353-359.

Yeo, S. F., Huie, S., Sofair, A. N., Campbell, S., Durante, A. \& Wong, B. (2006). Measurement of serum D-arabinitol/creatinine ratios for initial diagnosis and for predicting outcome in an unselected, populationbased sample of patients with Candida fungemia. J Clin Microbiol 44, 3894-3899.

Zaoutis, T. E., Greves, H. M., Lautenbach, E., Bilker, W. B. \& Coffin, S. E. (2004). Risk factors for disseminated candidiasis in children with candidemia. Pediatr Infect Dis J 23, 635-641. 